\title{
Hepatoprotective effect of Livplus-A polyherbal formulation
}

\author{
Rajesh Maheshwari*, Bhagyashree Pandya, Ramachandran Balaraman, Avinash Kumar Seth, Yogesh Chand Yadav and Vasa Siva Sankar \\ Department of Pharmacy, Sumandeep Vidyapeeth, Piparia, Vadodara, Gujarat, India.
}

\begin{abstract}
Objective: The aim of the present study was to investigate the hepatoprotective effect of Livplus (a polyherbal formulation) against $\mathrm{CCl}_{4}$-induced hepatotoxicity in rats. Methods: Hepatotoxicity was induced in rats by i.p. injection of $\mathrm{CCl}_{4}$ once three days for 14 days. Livplus or Silymarin was administered along with $\mathrm{CCl}_{4}$ and the biochemical parameters like aspartate aminotransferase (AST), alanine aminotransferase (ALT), alkalinephosphatase (ALP), total bilirubin (TB), direct bilirubin, total protein (TP), gamma-glutamyl transferase (GGT), total cholesterol (TC) and triglycerides (TG) were estimated. Furthermore, biomarkers of oxidative stress such as MDA levels, Glutathione contents, SOD and catalase activity in liver tissue were estimated. Results: Treatment with Livplus significantly reduced the elevated levels of ALT, AST, ALP, bilirubin (direct and total), GGT, TC, TG and increased levels of TP compared to $\mathrm{CCl}_{4}$ control rats. The treatment with Livplus also showed a significant increase in glutathione contents, SOD and catalase activity and a decrease in MDA levels compared to $\mathrm{CCl}_{4}$ control rats. Conclusion: The finding of present study indicates that Livplus showed a potential hepatoprotective activity. These results support the traditional use of Livplus in the treatment of liver disorders.
\end{abstract}

Key words: Livplus, $\mathrm{CCl}_{4}$, Hepatotoxicity, GGT, Hepatic enzymes.

\section{SUMMARY}

- Administration of Livplus $(100,200$ and $400 \mathrm{mg} / \mathrm{kg})$, a polyherbal formulation to the $\mathrm{CCl} 4$-induced hepatotoxicity resulted in a decrease the elevated levels of ALT, AST, ALP, bilirubin (direct and total), GGT, TC, TG, MDA and an increaselevels of TP, GSH, SOD, catalase activity compared to $\mathrm{CCl}_{4}$ control rats.

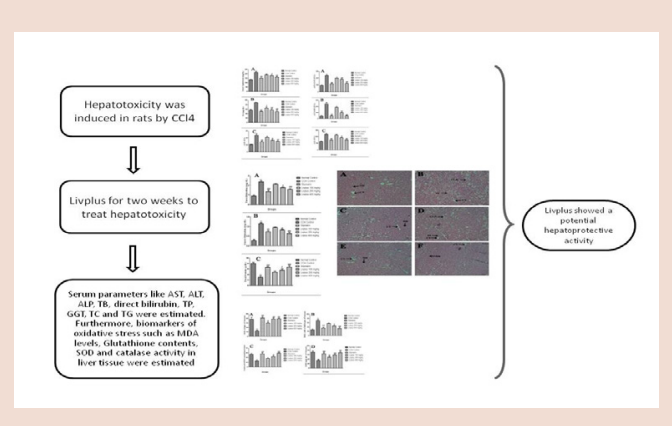

PICTORIAL ABSTRACT

Abbreviations used: AST: Aspartate aminotransferase, ALT: Alanine aminotransferase, ALP: Alkalinephosphatase, TB: Total bilirubin, TP: Total protein, GGT: Gamma-glutamyl transferase, TC: Total cholesterol, TG: Triglycerides. MDA: Malondialdehyde SOD: Super oxide dismuatse.

\section{Correspondence:}

Dr. Rajesh Maheshwari, Assistant Professor, Department of Pharmacy, Sumandeep Vidyapeeth, Piparia, Vadodara-391 760, Gujarat, India.

Email: rajpharma2007@gmail.com

DOI : 10.5530/pj.2015.5.11

\section{INTRODUCTION}

Liver is the most essential organ concerned with the biochemical activities in human body. The most important role is to detoxicate the toxic substances. ${ }^{1}$ The management of liver disorders is still a challenge. Therefore, the search for more effective and safer hepatoprotective drugs has continued to be an important area of active research. Since, there is no effective synthetic and conventional drugs are available, it has become a highly essential to search new drugs from herbal origin with little side effects. For a long time, herbal drugs are used for the treatment of liver diseases. ${ }^{2}$

At present there are various polyherbal formulations available in the market for the treatment of liver diseases. Livplus is one of the polyherbal formulations (Bacfo Pharmaceuticals India Limited, Noida) that consist of several herbal extracts mentioned in Table 1. It is used as hepatoprotective, hepato-stimulant and offers a compressive coverage of the treatment of liver diseases. ${ }^{3-9}$ But, this drug has not been proved as hepatoprotective drug in any experimental set up. Therefore, in present study we try to investigate hepatoprotective effect of Livplus against $\mathrm{CCL}_{4}$ - induced hepatotoxicity in rats.

\section{MATERIALS AND METHODS}

\section{Drugs and Chemicals}

Livplus was gifted by Bacfo Pharmaceuticals India Ltd., Noida (India). Silymarin was purchased from commercial market. All biochemical kits were purchased from Span Diagnostics Ltd., Surat (India). All other chemicals and reagents used in the study were of analytical grade.

\section{Experimental Animals}

Albino Wistar rats (200-250 g) of either sex were obtained from Zydus Research Centre, Ahmedabad. All animals were maintained under standardized condition (12-h light/dark cycle, $24 \pm 2^{\circ} \mathrm{C} \&$ humidity $35-60 \%$ ) and they were provided with standard pellet diet and water ad libitum. The rats were left for $48 \mathrm{~h}$ for adaptation prior to the beginning of the experiment. The study was approved by Institutional Animal Ethics Committee (IAEC) and carried out in accordance with CPCSEA (Committee for the Purpose of Control and Supervision of Experiment on Animal) guidelines.

\section{Acute toxicity study}

On the basis OECD guideline no. 423, the acute oral toxicity was carried out in albino Wistar rats of either sex weighing 200-250 g. ${ }^{10}$ Livplus was given at the dose of $(100,200,500,1000$ and $2000 \mathrm{mg} / \mathrm{kg}$, p.o.) for 3 animals and the signs and symptoms were observed after $0,30,60,120$, 180, $240 \mathrm{~min}$ and then once a day for next 14 days.

\section{Experimental design}

Carbon tetrachloride $\left(\mathrm{CCl}_{4}\right)$-induced acute hepatotoxicity in rats

Albino Wistar rats were divided into six groups, each group having six animals. Group I: Normal control animals were administered carboxy 
Table 1: Composition of Livplus (a polyherbal formulation)

\begin{tabular}{cccc}
\hline Ingredients & Botanical name & Part used & Weight $(\mathbf{m g})$ \\
\hline Bhringraja & Eclipta alba & Whole plant & 100 \\
Bhumiamla & Phyllanthus niruri & Whole plant & 100 \\
Kasni & Cichorium intybus & Whole plant & 75 \\
Katuka & Picrorhiza kurroa & Root & 75 \\
Punarnava & Boerhaavia diffusa & Whole plant & 50 \\
Daruharidra & Berberis aristata & Whole plant & 50 \\
Kalmegha & Andrographis paniculata & Whole plant & 50 \\
\hline
\end{tabular}

Bhawana Dravya: Processed in the fruit extract of Piper longum, fruit extract of Pipernigrum, rhizome extract of zingiber officinale (Trikatu), whole plant extract of Boerhaavia diffusa (punarnava) and whole plant extract of Cichorium intybus (Kasni).

methyl cellulose ( $1 \mathrm{~mL} / \mathrm{kg}$ of $1 \%$, w/v, p.o.); Group II: Carbon tetrachloride ( $1 \mathrm{~mL} / \mathrm{kg}$, i.p.); Group III: Silymarine (100 mg/kg, p.o.); Group IV, V and VI: Livplus (100, 200 and $400 \mathrm{mg} / \mathrm{kg}$, p.o. in $1 \% \mathrm{w} / \mathrm{v}$ of CMC), respectively. Livplus or silymarin was given daily for two weeks of respective groups, while carbon tetrachloride was given simultaneously every $72 \mathrm{~h}$ for 14 days except in group I. ${ }^{11}$

At the end of the experiments, blood samples were collected from the retro orbital plexus of rats under light ether anaesthesia, using glass capillaries. For separation of serum blood was allowed to clot for 15 minutes and it was then centrifuged at $5000 \mathrm{rpm}$ for 20 minutes. The serum was stored at $-20^{\circ} \mathrm{C}$ until further biochemical estimation. Serum was used for analysis of various biochemical parameters including, aspartate aminotransferase (AST), alanine aminotransferase (ALT), alkaline phosphate (ALP), total bilirubin (TB), direct bilirubin, total protein (TP), gamma-glutamyl transferase (GGT), total cholesterol (TC) and triglycerides (TG).

\section{Estimation of biomarkers of oxidative stress}

Liver was removed and kept in autoclaved inverted petridis in cold conditions. The tissues were cross chopped with surgical scalpel into fine slices in chilled $0.25 \mathrm{M}$ sucrose, quickly blotted on a filter paper. They were minced and homogenized in $10 \mathrm{mM}$ Tris- $\mathrm{HCl}$ buffer, $\mathrm{pH}$ 7.4 (10 $\%$ w/v) with 25 strokes of tight Teflon pestle of glass homogenizer at a speed of $10,000 \times \mathrm{g}$ at $0^{\circ} \mathrm{C}$ using the Remi cooling centrifuge. The clear supernatant obtained was used for assay of lipid peroxidation MDA (malondialdehyde) content, endogenous anti-peroxidative enzymes such as superoxide dismutase (SOD), catalase and GSH (glutathione). Lipid peroxidation or MDA formation, ${ }^{12}$ SOD activity, ${ }^{[13}$ catalase activity ${ }^{14}$ and $\mathrm{GSH}^{15}$ were estimated.

Histopathology

After sacrifice, liver tissue of each group was rapidly dissected out and washed immediately with saline and fixed in $10 \%$ phosphate buffered formalin. Paraffin-embedded specimens were cut into $5 \mu \mathrm{m}$-thick sections and stained with hematoxylin and eosin ( $\mathrm{H} \& \mathrm{E})$. The sections were examined under the light microscope (Olympus BX10, Tokyo, Japan) for the presence of histopathological changes and photomicrographs (Olympus DP12 camera, Japan) were taken. The observer performing histopathological evaluation was blinded to the animal treatment groups.

\section{Statistical analysis}

All of the data are expressed as mean \pm SEM. Statistical significance between more than two groups was tested using one-way ANOVA followed by the Bonferroni multiple comparisons test as appropriate using computer based fitting program (Prism, Graphpad 5). The significance level was set at $\mathrm{P}<0.05$ for all tests.

\section{RESULTS}

\section{Acute oral toxicity}

The oral administration of Livplus in rats up to the dose $2000 \mathrm{mg} / \mathrm{kg}$ did not show any sign of toxicity and no mortality for 14 days. It was shown that Livplus was safe up to oral dose of $2000 \mathrm{mg} / \mathrm{kg}$ of body weight. The experimental protocol was carried out using $1 / 20^{\text {th }}(100 \mathrm{mg} / \mathrm{kg}), 1 / 10^{\text {th }}$ $(200 \mathrm{mg} / \mathrm{kg})$ and $1 / 5^{\text {th }}(400 \mathrm{mg} / \mathrm{kg})$ dose based on toxicity study.

\section{Effect of Livplus on AST, ALT and ALP in $\mathrm{CCl}_{4}$-induced hepatotoxicity} in rats

There was a significant $(P<0.001)$ increase in the levels of AST, ALT and ALP in $\mathrm{CCl}_{4}$ control rats as compared to normal control rats. In contrast, the treatment with Livplus at the dose of $100 \mathrm{mg} / \mathrm{kg}$ showed a significant $(P<0.05)$ reduction in AST and ALT levels as compared to $\mathrm{CCl}_{4}$ control rats. However, the treatment with Livplus at the dose of 200 and $400 \mathrm{mg} / \mathrm{kg}$ or silymarin $(100 \mathrm{mg} / \mathrm{kg})$ showed a greater significant $(P<0.001)$ reduction in AST and ALT levels as compared to $\mathrm{CCl}_{4}$ control rats (Figure $\left.1 \mathrm{~A}-\mathrm{B}\right)$.

The treatment with Livplus $(200 \mathrm{mg} / \mathrm{kg})$ showed a significant $(P<0.01)$ decrease in ALP levels as compared to $\mathrm{CCl}_{4}$ control rats, while the $\mathrm{CCl}_{4}$ control rats treated with Livplus $(400 \mathrm{mg} / \mathrm{kg})$ or silymarin $(100 \mathrm{mg} / \mathrm{kg})$ showed more significant $(P<0.001)$ reduction in ALP levels as compared to $\mathrm{CCl}_{4}$ control group. However, Livplus $(100 \mathrm{mg} / \mathrm{kg})$ treated rats did not show any significant difference in the levels of ALP as compared to $\mathrm{CCl}_{4}$ control group (Figure 1C).

Effect of Livplus on total bilirubin, direct bilirubin and total protein in $\mathrm{CCl}_{4}$-induced hepatotoxicity in rats

$\mathrm{CCl}_{4}$ control rats showed a significant $(P<0.001)$ increase in the levels of TB and direct bilirubin in $\mathrm{CCl}_{4}$ control rats as compared to normal control rats. However, the treatment with Livplus (200 and $400 \mathrm{mg} /$ $\mathrm{kg})$ showed a significant reduction in TB $(P<0.05 ; P<0.001)$ and direct bilirubin $(P<0.01 ; P<0.001)$ levels as compared to $\mathrm{CCl}_{4}$ control rats. In contrast, the treatment with Livplus $(100 \mathrm{mg} / \mathrm{kg})$ did not show any significant change in TB and direct bilirubin levels as compared with $\mathrm{CCl}_{4}$ control group (Figure 2A-B).

There was a significant $(P<0.001)$ reduction in the levels of TP in $\mathrm{CCl}_{4}$ control rats as compared to normal control rats. In contrast, the treatment with Livplus $(200$ and $400 \mathrm{mg} / \mathrm{kg})$ showed a significant $(P<$ $0.05 ; P<0.001)$ increase in TP levels as compared to $\mathrm{CCl}_{4}$ control rats, but Livplus $(100 \mathrm{mg} / \mathrm{kg})$ treated rats did not show any significant alteration in the levels of TP as compared with $\mathrm{CCl}_{4}$ control group (Figure 2C).

Effect of Livplus on total cholesterol, triglycerides and GGT in $\mathrm{CCl}_{4}-$ induced hepatotoxicity in rats

In $\mathrm{CCl}_{4}$ control rats, TC and TG levels were significantly $(\mathrm{P}<0.001)$ increased when compared to normal control rats. The treatment with Liv- 

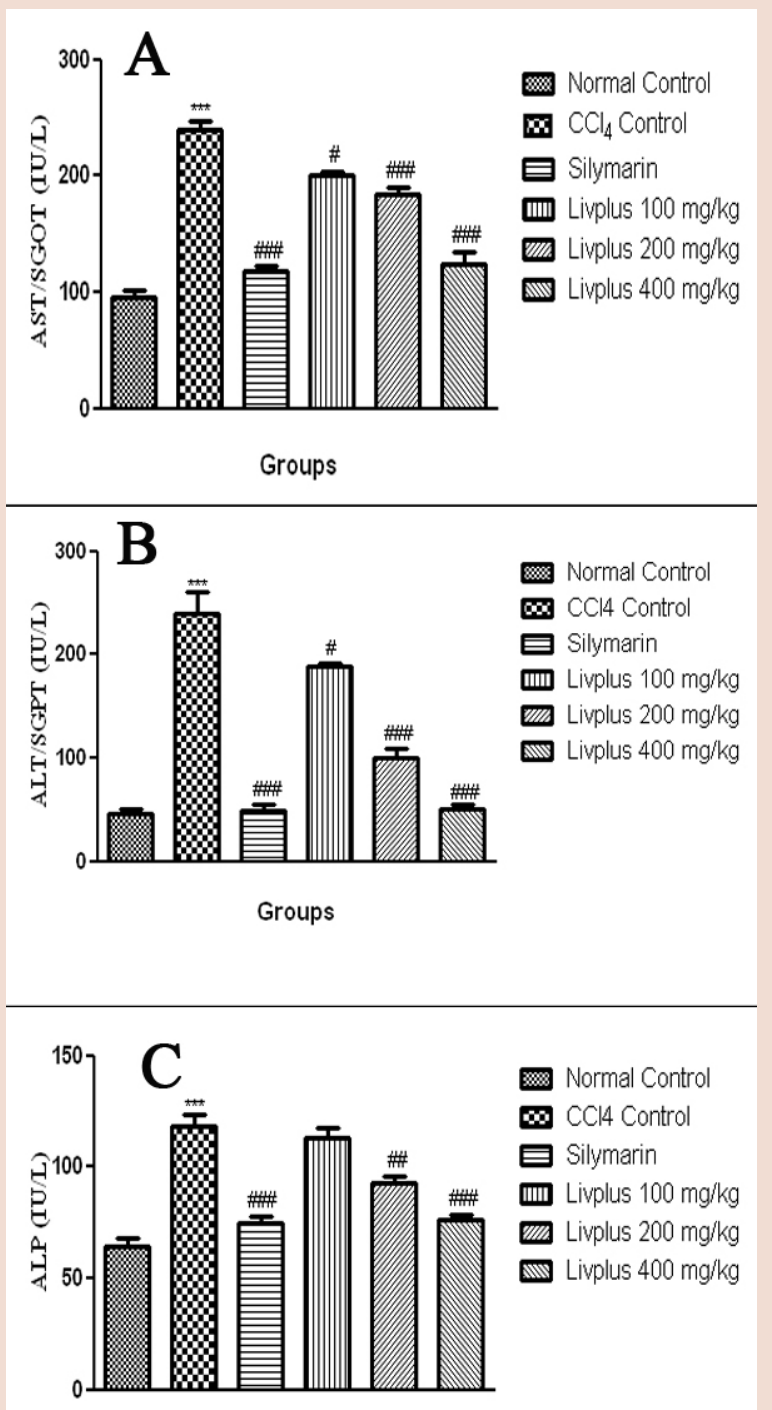

Groups

Figure 1: Effect of Livplus on serum (A) AST, (B) ALT and (C) ALP in $\mathrm{CCl}_{4}^{-}$ induced hepatotoxicity in rats

Values are expressed as Mean + S.E.M $(n=6)$. Where, ${ }^{* * *} \mathrm{P}<0.001$ as compared to normal control; ${ }^{\#} P<0.05,{ }^{\# \# P}<0.01,{ }^{\# \#} P<0.001$ as compared to $\mathrm{CCl}_{4}$ control

plus (200 and $400 \mathrm{mg} / \mathrm{kg}$ ) showed a significant $(P<0.05$; $P<0.001)$ reduction in TC levels as compared to $\mathrm{CCl}_{4}$ control rats. The treatment with Livplus $(100 \mathrm{mg} / \mathrm{kg})$ did not show any significant change in the levels of TC as compared with $\mathrm{CCl}_{4}$ control group. Moreover, the treatment with Livplus (100, 200 and $400 \mathrm{mg} / \mathrm{kg})$ showed a significant $(P<0.05 ; P$ $<0.001 ; P<0.001)$ reduction in TG levels as compared to $\mathrm{CCl}_{4}$ control rats (Figure 3A-B).

$\mathrm{CCl}_{4}$ control rats showed a significant $(P<0.001)$ increase in GGT level as compared to normal control rats. In contrast, the treatment with Livplus (200 and $400 \mathrm{mg} / \mathrm{kg})$ showed a significant $(P<0.01 ; P<0.001)$ reduction in GGT levels as compared to $\mathrm{CCl}_{4}$ control rats, while rats treated with $100 \mathrm{mg} / \mathrm{kg}$ did not show any significant difference in the levels of GGT as compared with $\mathrm{CCl}_{4}$ control group (Figure $3 \mathrm{C}$ ).
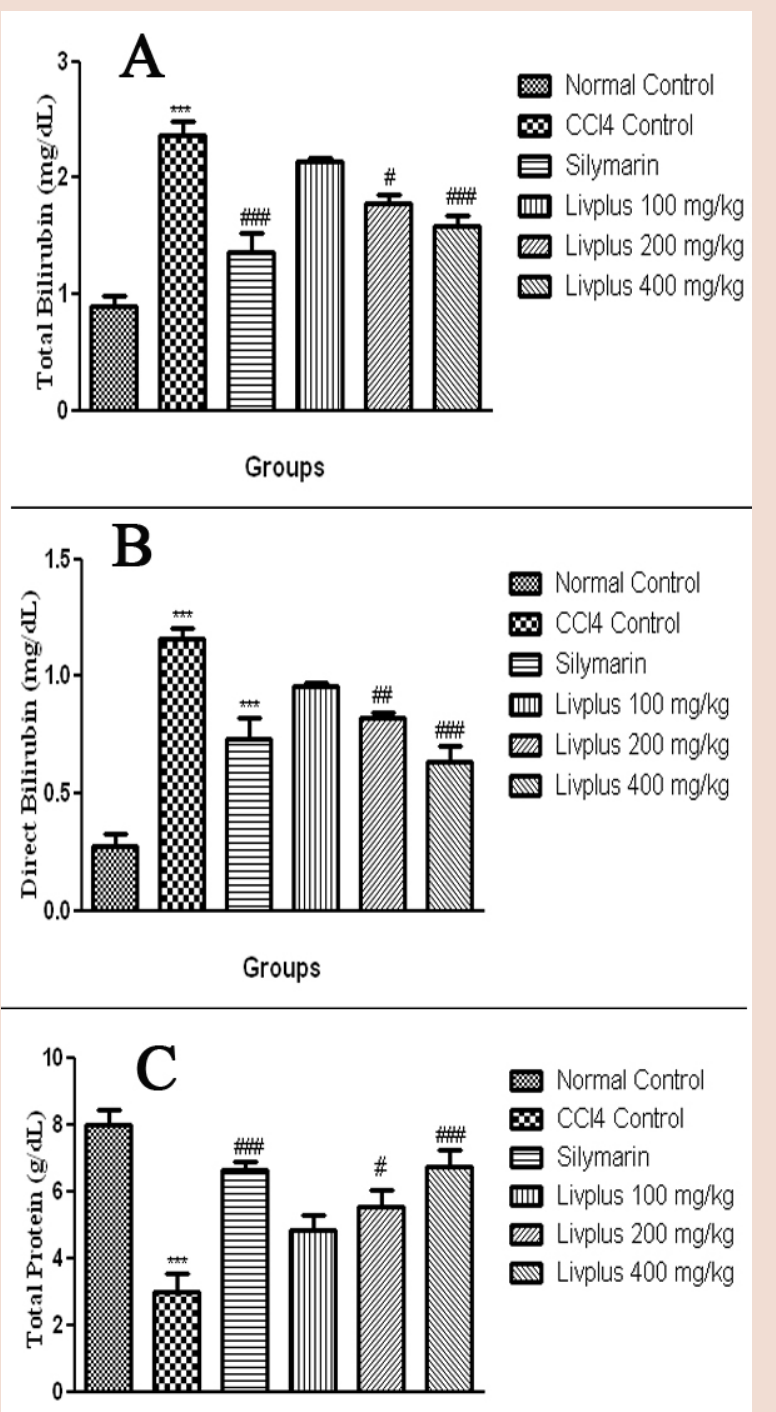

Groups

Figure 2: Effect of Livplus on (A) total bilirubin, (B) direct bilirubin and (C) total protein in $\mathrm{CCl}_{4}$-induced hepatotoxicity in rats

Values are expressed as Mean + S.E.M $(n=6)$. Where, ${ }^{* * * P}<0.001$ as compared to normal control; ${ }^{P} P<0.05,{ }^{\# \# P}<0.01,{ }^{\# \#} P<0.001$ as compared to $\mathrm{CCl}_{4}$ control

Effect of Livplus on SOD, MDA, catalase and GSH in $\mathrm{CCl}_{4}$-induced hepatotoxicity in rats

In $\mathrm{CCl}_{4}$ control group, $\mathrm{SOD}$, catalase and GSH levels were significantly $(P<0.001)$ decreased as compared to normal control rats. In contrast, the treatment with Livplus $(100,200$ and $400 \mathrm{mg} / \mathrm{kg})$ showed a significant increase in SOD $(P<0.01 ; P<0.001 ; P<0.001)$ and GSH $(P<0.01 ; P<0.001$; $P<0.001)$ levels as compared to $\mathrm{CCl}_{4}$ control rats. In addition, treatment with Livplus (200 and $400 \mathrm{mg} / \mathrm{kg})$ showed a significant $(P<0.05$; $P<0.001)$ increase in catalase activity as compared to $\mathrm{CCl}_{4}$ control rats, while animals treated with $100 \mathrm{mg} / \mathrm{kg}$ did not show any significant effect in the levels of catalase as compared with $\mathrm{CCl}_{4}$ control group.

The content of MDA, end product of lipid peroxidation was significantly $(\mathrm{P}<0.001)$ increased in liver tissue of $\mathrm{CCl}_{4}$ control rats as compared to normal control rats. The treatment with Livplus (200 and $400 \mathrm{mg} / \mathrm{kg}$ ) 

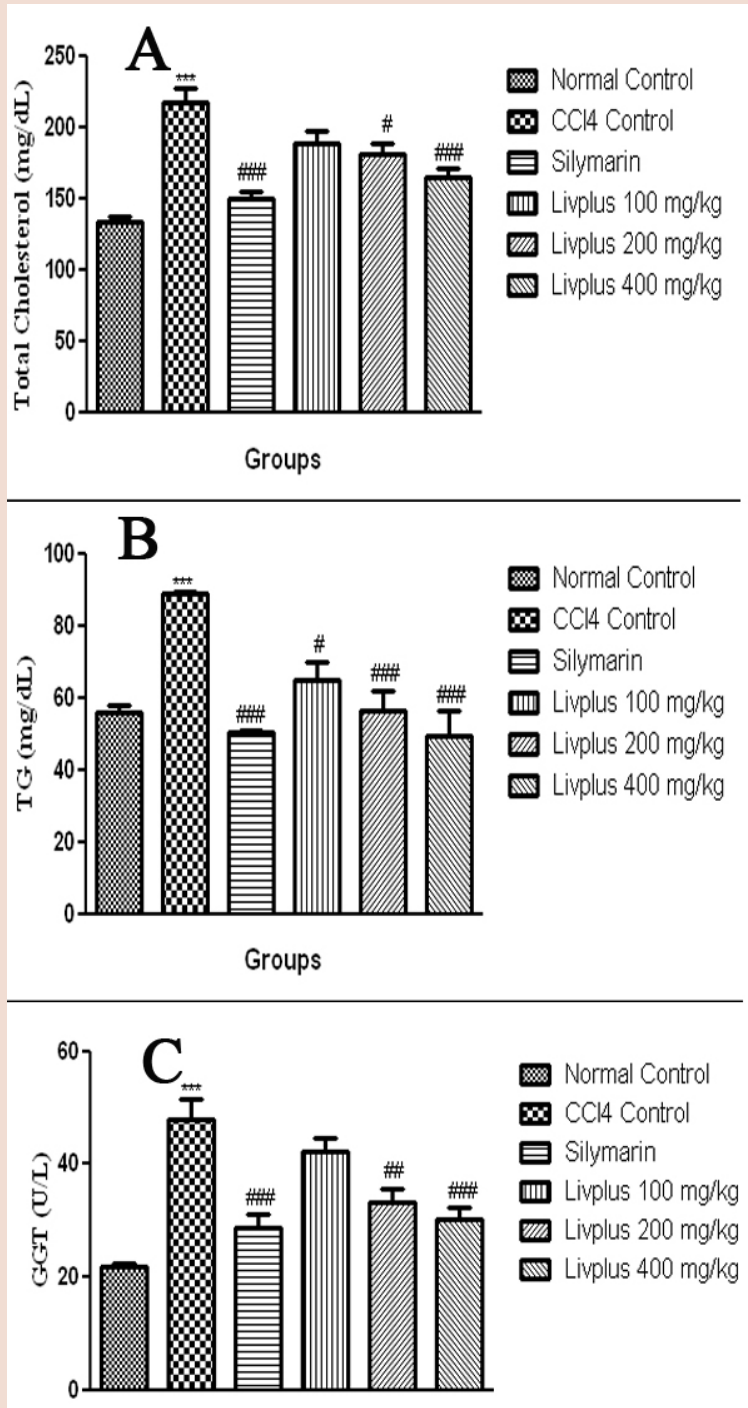

Groups

Figure 3: Effect of Livplus on (A) total Cholesterol, (B) triglycerides and (C) $\mathrm{GGT}$ in $\mathrm{CCl}_{4}$-induced hepatotoxicity in rats

Values are expressed as Mean + S.E.M $(n=6)$. Where, ${ }^{* * *} P<0.001$ as

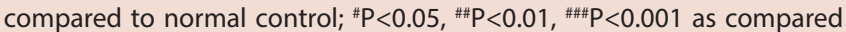
to $\mathrm{CCl}_{4}$ control

showed a significant $(P<0.05 ; P<0.001)$ reduction in MDA levels as compared to $\mathrm{CCl}_{4}$ control rats, but Livplus $(100 \mathrm{mg} / \mathrm{kg})$ treated rats did not show any significant reduction in the levels of MDA as compared to $\mathrm{CCl}_{4}$ control group (Figure 4A-D).

\section{Histopathological observation}

The histological profile of the hepatic tissue of the normal control animals showed a normal lobular architecture. Normal hepatocytes were arranged in single cell cords radiating away from a central vein (A). $\mathrm{CCl}_{4}$ treated rats showed disturbed liver architecture, exhibiting central lobular necrosis with tiny vacuoles, and fatty infiltrations (B). $\mathrm{CCl}_{4}$ control rats treated with silymarin and Livplus $(400 \mathrm{mg} / \mathrm{kg})$ retained normal hepatic tissue architecture, so received significant protection from $\mathrm{CCl}_{4}$-induced hepatic damage (C and F). $\mathrm{CCl}_{4}$ control rats treated with Livplus $(200 \mathrm{mg} /$ $\mathrm{kg}$ ) showed minimal inflammatory cellular infiltration, regeneration of hepatocytes around central vein was also observed and almost near normal liver architecture (E), while Livplus (100 mg/kg) treated did not show any significant hepatic tissue architectural changes (D) (Figure 5A-F).

\section{DISCUSSION}

Liver is one of the vital organs in animal body and plays a central role in transforming and clearing the chemicals, but it is susceptible to toxicity of several agents including drugs and chemicals. More than 900 drugs have been reported to cause liver injury. ${ }^{16}$ Carbon tetrachloride is one of the most commonly used chemical for the screening of hepatoprotective drugs. Therefore, administration of $\mathrm{CCl}_{4}$ can lead to enzymatic activation, mainly by $\mathrm{CYP}_{2} \mathrm{E}_{1}$, into trichloromethyl free radicals $\left(\mathrm{CCl}_{3}\right)$ inside the membrane of the endoplasmic reticulum. This is followed by chloromethylation, peroxidation and progressive destruction of the unsaturated fatty acid of the endoplasmic reticulum membrane phospholipids. These methods are known as lipid peroxidation, ultimately it is responsible for functional and structural disruption of hepatocytes. ${ }^{17}$ In liver damage, cellular enzymes such as AST, ALT, ALP, bilirubin (direct and total) will escape into the serum resulting in elevation of the their serum concentration. Histology of liver showed disturbed liver architecture, exhibiting central lobular necrosis with tiny vacuoles, and fatty infiltrations.$^{18}$ Reduction of glutathione content, SOD activity, catalase activity and increased in lipid peroxidation is a markers for the hepatic damage. ${ }^{19-21}$

The treatment with Livplus (200 and $400 \mathrm{mg} / \mathrm{kg}$, p.o.), silymarin (100 $\mathrm{mg} / \mathrm{kg}$, p.o.) for 14 days showed a significant protection against $\mathrm{CCl}_{4}-$ induced liver damage by in virtue of reduction in cellular enzymes like AST, ALT, ALP, bilirubin (direct and total). It's hepatoprotective effect is also confirmed by prevention of histological changes caused by $\mathrm{CCl}_{4}$ The possible mechanism of action may be associated with inhibition of $\mathrm{CYP}_{2} \mathrm{E}_{1}$ activity. In present study, $\mathrm{CCl}_{4}$ control rats showed a significant increase in MDA levels and a decrease in glutathione content, SOD activity, catalase activity as compared to normal control rats. However, the treatment with Livplus (200 and $400 \mathrm{mg} / \mathrm{kg}$, p.o.) or silymarin (100 mg/ $\mathrm{kg}$, p.o.) showed a significant reduction in MDA levels and an increase in glutathione content, SOD activity and catalase activity as compared to $\mathrm{CCl}_{4}$ control rats.

It was previously reported that administration of $\mathrm{CCl}_{4}$ caused the decrease in number of hepatocytes which in turn might result into decreased hepatic capacity to synthesize protein and glycogen. But, when Livplus was given along with $\mathrm{CCl}_{4}$ there was a significant increase in total protein which may be due to the hepatoprotective effect. ${ }^{22}$ In previous study, it was also reported that Gamma GT (Gamma-Glutamyl Transpeptidase) was significantly increased in rat intoxicated with $\mathrm{CCl}_{4}$ in comparison with normal control group. ${ }^{23}$ GGT which is present in the membrane of endoplasmic reticulum of the hepatocytes. When it is released extensively from damaged hepatic cell to the bloodstream is considered a good diagnostic profile for hepatic damage. In present study, there was a significant increase in the level of GGT in $\mathrm{CCl}_{4}$ control group, while Livplus treated animals restored the levels of GGT. Administration of $\mathrm{CCl}_{4}$ control rats caused a significant increase in TC and TG levels. ${ }^{24}$ The treatment with Livplus showed a significant reduction in TC and TG levels. In current study, a comparative histopathological study of the liver from various treatments further supported the hepatoprotective potential.

\section{CONCLUSION}

These results showed that Livplus (200 and $400 \mathrm{mg} / \mathrm{kg}$ ) showed a significant protection in dose dependant manner against experimentally induced hepatotoxicity. The possible mechanism behind the hepatoprotective effect of Livplus might be associated with inhibition of $\mathrm{CYP}_{2} \mathrm{E}_{1}$ activity and stimulation of antioxidant defense mechanism against the free radicals generated by $\mathrm{CCl}_{4}$. Therefore, it was concluded that Livplus has a significant hepatoprotective effect. Our present investigation sup- 


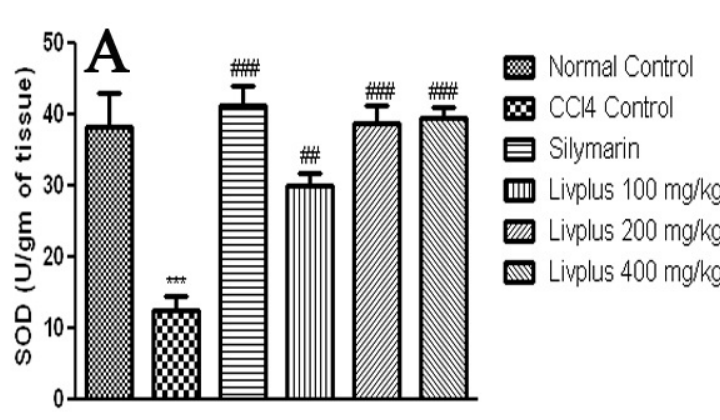

Groups

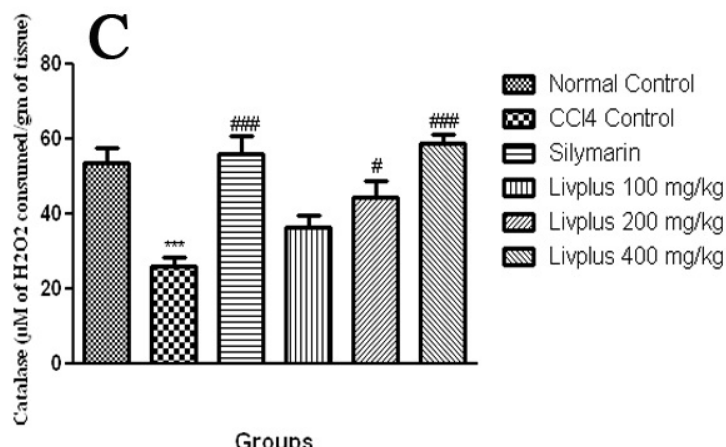

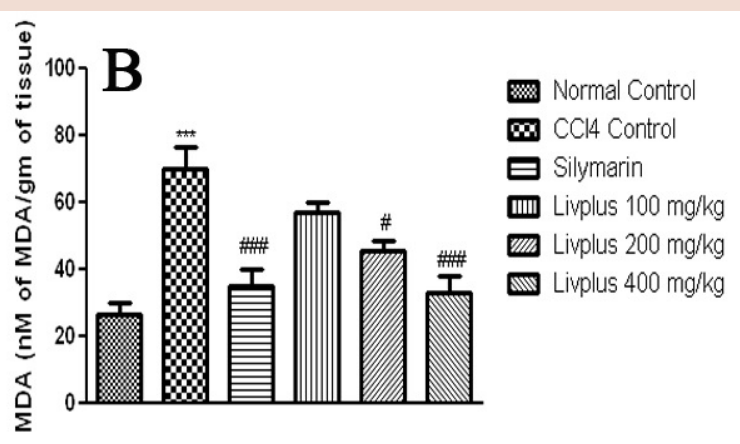

Groups

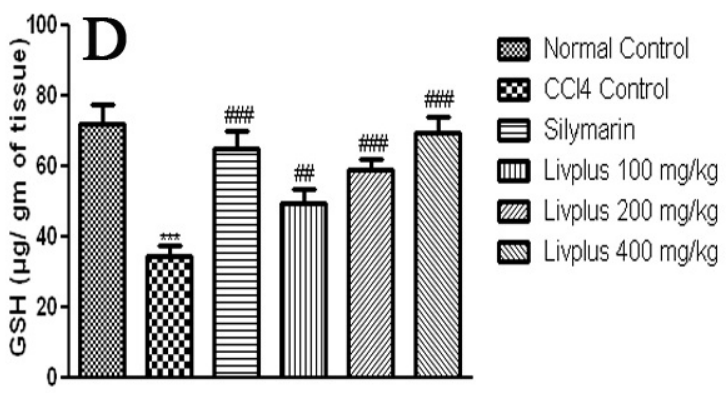

Groups

Figure 4: Effect of Livplus on (A) SOD, (B) MDA, (C) Catalase and (D) GSH in $\mathrm{CCl}_{4}$-induced hepatotoxicity in rats

Values are expressed as Mean + S.E.M $(n=6)$. Where, ${ }^{* * *} P<0.001$ as compared to normal control; ${ }^{*} P<0.05,{ }^{* \# P}<0.01,{ }^{\# \# * P}<0.001$ as compared to $\mathrm{CCl}_{4}$ control
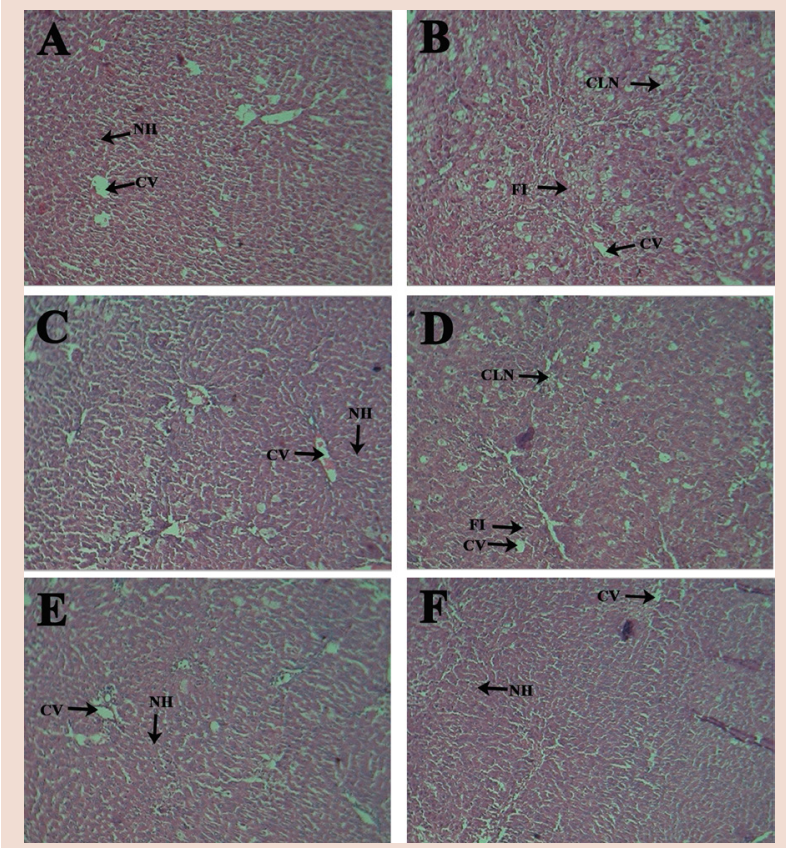

Figure 5: Effect of Livplus on histopathological changes in albino Wistar rat liver

(A) Normal control; (B) $\mathrm{CCl}_{4}$ control; (C) Silymarine $+\mathrm{CCl}_{4}$ treatment; (D) Livplus $100 \mathrm{mg} / \mathrm{kg}+\mathrm{CCl}_{4}$ treatment; (E) Livplus 200 $\mathrm{mg} / \mathrm{kg}+\mathrm{CCl}_{4}$ treatment; (F) Livplus $400 \mathrm{mg} / \mathrm{kg}+\mathrm{CCl}_{4}$ treatment. Hematoxylin and eosin stain, CLN: central lobular necrosis; CV: central vein; Fl: fatty infiltration; $\mathrm{NH}$ : normal hepatocytes ports the traditional use of Livplus in the treatment of hepatotoxicity.

\section{ACKNOWLEDGEMENT}

We are sincerely thankful to Bacfo Pharmaceuticals India limited, Noida for providing financial support and their product sample to carry out the study.

\section{CONFLICTS OF INTEREST}

We declare that we have no conflict of interest.

\section{REFERENCES}

1. Shahani S. Evaluation of hepatoprotective efficacy of APCL-A polyherbal formulation in vivo in rats. Indian Drugs. 1996; 36: 628-31.

2. Venkateswaran S, Pari L, Viswanathan P, Menon VP. Protective effect of Livex, a herbal formulation against erythromycin estolate-induced hepatotoxicity in rats. $J$ Ethnopharmacol. 1997; 57(3): 161-7.

3. Saxena AK, Singh B, Anand KK. Hepatoprotective effects of Eclipta alba on subcellular levels in rats. J Ethnopharmacol. 1993; 40(3): 155-61.

4. Ahmed B, Al-Howiriny TA, Siddiqui AB. Antihepatotoxic activity of seeds of Cichorium intybus. J Ethnopharmacol. 2003; 87(2-3): 237-40.

5. Anandan R, Devaki T. Hepatoprotective effect of Picrorrhiza [sic] kurroa on tissue defense system in D galactosamine-induced hepatitis in rats. Fitoterapia. 1999; 70 54-7.

6. Chandan BK, Sharma AK, Anand KK. Boerhavia diffusa: a study of its Hepatoprotective activity. J Ethnopharmacol. 1991; 31(3): 299-307.

7. Gilani AH, Janbaz KH. Prevention of acetaminophen-induced liver damage by Berberis aristata leaves. Biochem Soc Trans. 1992; 20(4): 347.

8. Handa SS, Sharma A. Hepatoprotective activity of andrographolide from Andrographis paniculata against carbontetrachloride. Indian J Med Sci. 1990; 92: 276-83.

9. Harish R, Shivanandappa T. Antioxidant activity and hepatoprotective potential of Phyllanthus niruri. Food Chem. 2006; 95(2): 180-5.

10. OECD, 2002. Acute oral toxicity. Acute oral toxic class method guideline 423 adopted 23.03.1996. In: Eleventh Addendum To The OECD Guidelines for the Testing of Chemicals Organisation for Economical Co-Operation and Development, Paris, June; 2000. 
11. Shakya A, Sharma N, Saxena M, Shrivastava S, Shukla S. Evaluation of the antioxidant and hepatoprotective effect of Majoon-e-Dabeed-ul-ward against carbon tetrachloride induced liver injury. Exp Toxicol Pathol. 2012; 64(7-8):767-3.

12. Slater TF, Sawyer BC. The stimulatory effect of carbon tetrachloride and other halogenalkane or peroxidative reaction in the rat liver functions in vitro. Biochem J. 1971; 123(5): 805-15.

13. Mishra HP, Fridovich I. The role of superoxide anion in the autooxidation of epinephrine and a simple assay of superoxide dismutase. J Biol Chem. 1972; 247(10): 3170-5

14. Aebi H. Catalase in vivo. Meth Enzymol. 1984; 105: 121-6.

15. Moron MS, Depierre JW. Levels of glutathione, glutathione reductase and glutathione $\mathrm{S}$ transferase activities in rat lung and liver. Biochim Biophys Acta. 1979; 582(1): 67-78.

16. Friedman SE, Grendell JH, McQuaid KR. Current diagnosis and Treatment in gastroenterology. New York: Lang Medical Books/McGraw-Hill; 2003.

17. SlaterTF. Biochemical mechanism of liver injury. London: Academic Press; 1965.

18. Rajib AM, Monirul IK, Jahan BI, Ashik MM, Ekramul H. Hepatoprotective activity of methanol extract of some medicinal plants against $\mathrm{CCL}_{4}$-induced hepa- totoxicity in rats. Eur J Scientific Res. 2009; 37(3): 302-10.

19. Recknagael R. Carbon tetrachloride hepatotoxicity. Pharmacological Review 1967; 19(2):145-96.

20. Kamiyama T, Sato C, Liu J. Role of lipidperoxidation in acetaminophen induced hepatotoxicity; comparison with carbontetrachloride. Toxicol Lett. 1993; 66: 7-12.

21. Brattim WJ, Glenda EA Jr, Recknagel RO. Pathological mechanism in carbon tetrachloride hepatotoxicity. J Free Radical Bio Med. 1985; 1(1): 27-38.

22. Swathi P, Kumar TJ, Babu MM, Vijay Ch. Protective Responce of Methnolic Extract of Garcinia Indica Fruits on CCl4 Induced Liver Damage. Phcog J. 2010; 2(17): 47-52.

23. Leonard TB, Neptun DA, Popp JA. Serum gamma glutamyl transferase as a specific indicator of bile duct lesions in the rat liver. Am J Pathol. 1984; 116(2): 262-9.

24. Khan RA, Khan MR, Sahreen S. CCl4-induced hepatotoxicity: protective effect of rutin on p53, CYP2E1 and the antioxidative status in rat. BMC Complement Altern Med. 2012; 12: 178.

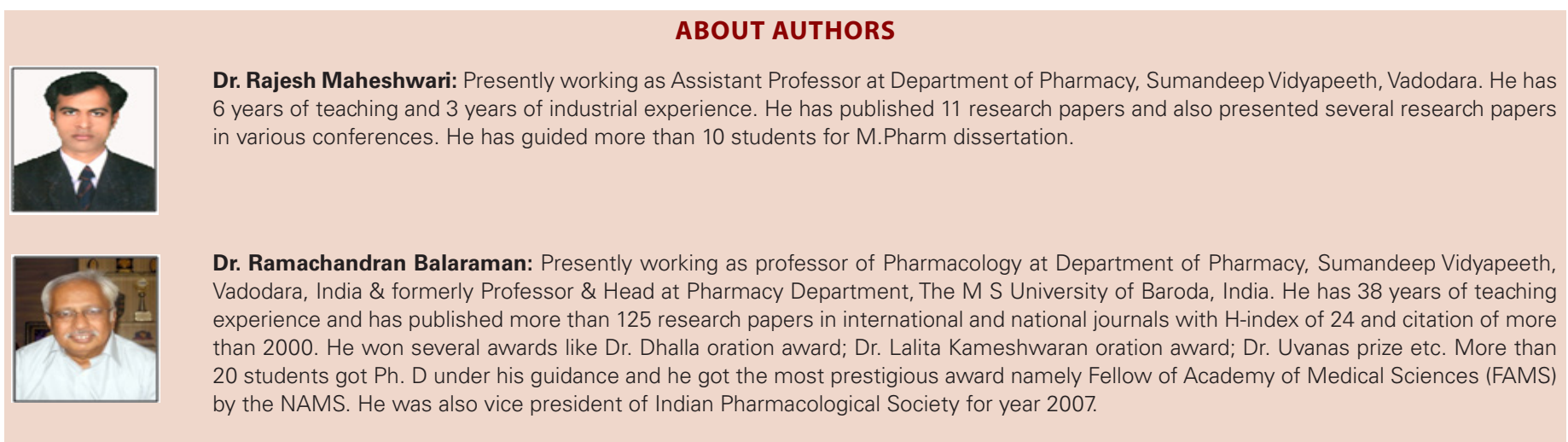

